\title{
Pediatric Tracheotomy: 5-years of Experiences at a Tertiary Care Center
}

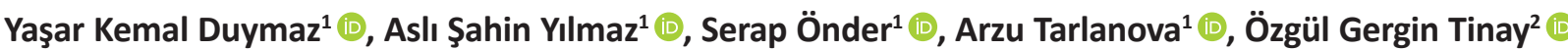

${ }^{1}$ University of Health Science, Umraniye Training and Research Hospital, Department of Otolaryngology, Istanbul, Turkey

${ }^{2}$ Medipol University, Department of Otolaryngology, Istanbul, Turkey

ORCID ID: Y.K.D. 0000-0002-4887-4677; A.Ş.Y. 0000-0002-7846-9453; S.Ö. 0000-0002-3576-0953; A.T. 0000-0001-9042-041X;

Ö.G.T. 0000-0002-4544-863X

Citation: Duymaz YK, Yilmaz AS, Onder S, Tarlanova A, Tinay OG. Pediatric tracheotomy: 5-years of experiences at a tertiary care center. Tr-ENT 2021;31(3):66-69. https://doi.org/10.26650/Tr-ENT.2021.994998

\section{ABSTRACT}

Objective: To describe specific indications and complications of pediatric tracheostomies performed in our tertiary care children's hospital between 2015 and 2020.

Materials and Methods: A retrospective study analyzing charts of pediatric tracheostomies utilizing the maturation suture technique was conducted. The review included patient data covering a 5-year period, commencing on the $1^{\text {st }}$ of January 2015 through the $31^{\text {st }}$ of May 2020.

Results: Fifty-five patients ( 33 females, 22 male) were included in the study. A tracheostomy was performed to address complications arising from prolonged ventilation in 48 children (87\%) or upper airway obstruction in 7 children (13\%).

There was one intraoperative complication that resulted in death. There was one early postoperative complication (2\%) (one child suffered accidental decannulation and the cannula was replaced without further incident). There were 7 late postoperative complications all featuring peristomal granulation tissue (13\%). There were 16 deaths; however, only one resulted from the tracheostomy as outlined above. Eight patients (15\%) were successfully decannulated. In 6 cases, the tracheostomy was spontaneously closed. Repair of tracheoesophageal fistula was required in two patients.

Conclusion: Currently, the tracheostomy is the preferred course of treatment. Though it can potentially lead to severe complications in children, instances of this occurring are rare. Therefore, a tracheostomy should be performed by a multidisciplinary team following predetermined rules in a specialized center.

Keywords: Pediatric tracheotomy, maturation suture technique, upper airway obstruction

\section{INTRODUCTION}

The last 30 years has seen alterations in indications of tracheostomy in children $(1,2)$. In the past, the most common indications were acute inflammatory airway obstructions such as diphtheria or acute epiglottitis. The two pronged approach of vaccine development against Corynebacterium diphtheriae and Haemophilus influenzae as well as modern neonatal intensive care units have served to reduce the totality of infection based indications for a tracheostomy (3). Recent series have shown that prolonged ventilation or upper airway obstruction due to larygotracheal anomalies have become the most prevalent indications of pediatric tracheostomy (4).
The tracheostomy has many advantages, it is comfortable for patients, it requires less sedation, breathing is easier, long-term laryngeal function is improved, there is less need for mechanical ventilation, there is a lower risk of ventilatorassociated pneumonia, it results in earlier discharging from PICU and improved oral hygiene $(5,6)$.

Tracheostomy complications include subcutaneous emphysema, hemorrhage, accidental decannulation, pneumothorax, pneumomediastinum, intratracheal mucosal plugs, occlusion of the tracheostomy tube with mucus, granuloma around the tracheostomy and infections such as tracheitis $(3,7)$.

Corresponding Author: Yaşar Kemal Duymaz E-mail: dryasarkemalduymaz@gmail.com

Submitted: $15.09 .2021 \bullet$ Accepted: 05.10.2021 • Published Online: 04.11 .2021

This work is licensed under Creative Commons Attribution-NonCommercial 4.0 International License. 
The purpose of the study is to describe primary indication and complications of tracheostomy utilizing the maturation suture technique performed in children between 2015-2020, in our tertiary care children's hospital.

\section{MATERIALS AND METHODS}

A retrospective study analyzing charts of patients that underwent pediatric tracheostomy utilizing the maturation suture technique was conducted at the tertiary care children's hospital. In this study, we reviewed the patient data of a 5-year period, from January 1 2015, through May 312020. The hospital ethics committee approved the study.

Charts were reviewed for demographic data such as gender and age at tracheostomy, indication of tracheostomy, date of tracheostomy, last clinical examination, mortality and comorbidities such as preterm birth, congenital heart disease, bronchopulmonary dysplasia, neurologic, neuromuscular or neoplastic disease, known syndrome, severe systemic infection. Tracheostomy indications were separated into 2 groups: 1 ) long intubation, and 2) upper airway obstruction. Patients with incomplete medical records or age $>18$ years at the time of tracheostomy were excluded from this study.

\section{Surgical procedure}

The same technique was used in all patients. During the tracheostomy, general anesthesia was applied to all childrens.. The patient was placed in a supine position and extension of the neck was supported by a shoulder roll. A horizontal skin incision was performed on the midpoint between the cricoid cartilage and the sternal notch. Cervical lipectomy was performed. The platysma was divided, midline raphe between the strap muscles was encountered, strap muscles were retracted laterally with regular finger palpation to secure the medial positioning of the trachea. After division of the thyroid gland, the pretracheal fascia was identified. The cricoid cartilage was palpated superiorly after loose fascia was excised bluntly from the anterior trachea. Two traction sutures with 4-0 vicryl were placed at the 3rd or 4th tracheal rings on either side of the. The tracheal incision was made vertically between the sutures. We placed four maturity sutures (with 4-0 PDS) between the trachea and the skin. The tracheostomy cannula was inserted and secured by a twine and tightened around the neck.

After surgery, the patient was promptly admitted to the intensive care unit (ICU). An AP thoracic X-ray was performed to establish the place of the cannula and the absence of pneumothorax or pneumomediastinum.

Patients were decannulated when they no longer required mechanical ventilation, nasal oxygen and no longer suffered from airway obstruction. Our decannulation protocol mandates the following: direct laryngoscopy and bronchoscopy are preformed to rule out airway stenosis, suprastomal collapse and granulation. Afterwards, a one size smaller cannula is placed, plugged and the patient is observed in the ward for 2 days before being discharged. If the patient can tolerate the plugged cannula for 3 weeks, the patient is then readmitted before undergoing direct laryngoscopy and tracheoscopy again. If no airway obstruction is present, the same cannula is placed after which the patient can return to the ward. Decannulation is then performed and the patient is observed for three days before being discharged. The final direct laryngoscopy and tracheoscopy is performed six weeks thereafter.

\section{RESULTS}

Fifty-five patients (33 female, 22 male) were included in the study. The median age at tracheostomy was 24, 2 months (range 1 month to 11 years). Thirty-six patients underwent tracheostomies within the first year of life (Graphic 1).

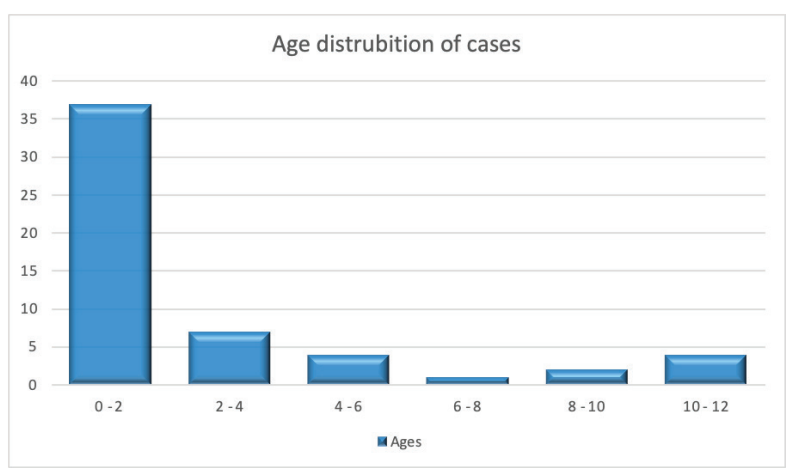

Figure 1: Age distribution of cases.

There were two main indications for tracheostomy: prolonged intubation and airway obstruction. Primary indications in 48 patients with prolonged intubation were cardiopulmonary disease $(n=23)$, neuromuscular disease $(n=24)$ and chronic aspirations $(n=1)$. In patients with airway obstruction, 4 resulted from subglottic stenosis, 2 from Pierre-Robin's syndrome and 1 from bilateral vocal cord paralysis.

There was one intraoperative complication that resulted in death. The child had a tracheoesophageal fistula due to long intubation. The tracheoesophageal fistula was not noticeable prior to the tracheostomy. After the tracheostomy was performed, uninterrupted air flow into the patient's stomach lead to the spotting of the fistula. However, the patient was lost because he was unable to respirate sufficiently. There was one early postoperative complication (2\%) where one child suffered accidental decannulation and the cannula was replaced without complications. There were 7 late postoperative complications all featuring peristomal granulation tissue (13\%).

There were 16 deaths; with only one being directly related to the tracheostomy as already outlined above. 15 patients suffered from cardiopulmonary arrest due to complications related to their disease.

We decannulated 8 patients (15\%) successfully. Mean duration from tracheotomy to decannulation was 176 days (range, 30 days to 455 days). In 6 of the cases, the tracheostomy closed spontaneously. Repair of the tracheoesophageal fistula was required in two patients. 


\section{DISCUSSION}

In our study, we retrospectively analyzed 55 patients who underwent tracheotomy between January 2015 and May 2020 using a maturation suture. 16 patients died, and of these patients, one death arose due to the complications related to the tracheostomy. 8 patients were decannulated successfully.

In our study, the ages of the patients spanned ranged from 0 to 11 years, with $62 \%$ of the pediatric patients being younger than 12 months old and of those, 53\% were younger than 6 months of age. Previous studies noted similar trends with patients in this lower age bracket featuring predominately in tracheostomies $(3,8,9)$. This study found the mean age of patients undergoing tracheostomy for both airway obstruction and prolonged ventilation to be similar. In support of this thesis a study by Nasif et al involving 57 pediatric tracheostomies performed between 2004-2014, reported no difference in the mean age of patients receiving tracheostomies for either airway obstruction or prolonged intubation (3). Conversely, another study which includes 122 pediatric tracheotomies between the years 1987-2003, Mahadevan et al. noted a mean age of 4.5 months for airway obstruction surgeries, versus 16 months for prolonged intubation (10).

Due to improvements in diagnosis and treatment, the survival rates of pediatric patients with chronic diseases have increased and these patients are managed in intensive care units under endotracheal intubation for a long period. Therefore prolonged intubation remains the leading indication necessitating tracheostomy (11-13). Tracheostomy, which is a part of palliative treatment in children with chronic diseases, enables patients to spend more time with their families whilst allowing them to be more comfortable (14). As in the literature, and confirmed by our study, the most common indication was prolonged intubation caused by cardiopulmonary diseases, neurological diseases, upper airway obstruction and craniofacial anomalies (15). Our series did not feature cases of tracheotomy for laryngeal trauma similar to studies that have taken place within the last decade, unlike studies that took place over 10 years ago $(3,13,16)$. This reduction is mostly likely due to increased car seat belt use. There were no indications for laryngeal infection or inflammation owing largely to vaccinations against $H$. influenzae type $B$ and diphtheria. In a series of 282 pediatric tracheostomies between 1968 and 2005, infection led to airway obstruction in 101 patients (16). Endotracheal tube improvements, notably in the selection of appropriate diameters, have resulted in fewer laryngeal complications, particularly in neonates $(6,17)$. Indications of tracheotomy for severe laryngomalacia, recurrent laryngeal papillomatosis and certain cases of subglottic stenosis have reduced arising from improvements in surgical techniques $(18,19)$. Lastly, propranolol is currently the preferred treatment for laryngeal hemangioma, after surmounting the preference for surgeries that used to be in favor $(20,21)$. After enhancements in non-invasive ventilation, the need for intubation and tracheostomy in some airway obstruction diagnoses, such as severe laryngomalacia or Pierre Robin sequence has relegated (23). Prolonged inbutation in immature children with bronchodysplasia, as well as airway obstruction caused by congenital or acquired bilateral vocal fold palsy, deformity, or malignancy, are currently the main indications $(9,13)$.

Although the frequency of pediatric tracheostomy has increased, death resulting from tracheostomy is extremely rare $(5,13,22)$. In a study which includes 420 pediatric tracheostomies, Wetmore et al. reported that the mortality rate was $28 \%$ in 1982 (1). Case mortalities are on the decline, there were 2 instances out of 57 for Nassif et al. (3), 2 out of 122 for Mahadevan et al.(10), 3 out of 282 for Ozmen et al. (16), 1 out of 112 for Trey et al. (9), and zero for Ang et al. (48 children) (8). Risks are not totally eradicated even with the presence of contemporary surveillance protocols such as cardiac and oxygen monitoring. In our series, one death occurred as a result of tracheoesophageal fistula.

In this case series, the early complication rate was $2 \%$. Where one child suffered accidental decannulation and the cannula was replaced without further incident. Early accidental decannulation was reported as $2.5 \%-3.7 \%$ in many studies $(10,23)$. Recannulation is prevented by tracheal suture tension on both sides of the incision. The maturation suture technique that secures the trachea to the skin, creating a formal, safe stoma, also helps recannulation (24).

Accidental decannulation, intratracheal mucosal plugs, and granuloma surrounding the tracheotomy and in the trachea, subglottic or tracheal stenosis occurring occasionally are late complications of pediatric tracheostomy. Our study returned a late complication rate of $13 \%$ (only granulation tissue), in contrast to other reports which had a complication rate of $31-51 \%(3,8,10,25)$.

The literature noted a decannulation rate that ranged between $17 \%$ and $78 \%$ depending on the variety of tracheotomy indications and associated comorbid diseases (25-28). In this study, 8 patients (15\%) were successfully decannulated a figure similar to that presented by the literature $(3,4,27-29)$.

\section{CONCLUSION}

Tracheostomy is performed in cases of prolonged ventilation and for airway obstruction. Currently tracheostomy is the preferred option, however, it can potentially lead to severe complications in children albeit rarely, therefore, it must be carried out by a multidisciplinary team following predetermined rules in a specialized center.

Ethics Committee Approval: University of Health Sciences Umraniye Training and Research Hospital Clinical Research Ethics Committee approved the study. Number: BAOAÄKH.4.34.H.GP.O.01/382

Informed Consent: Written informed consent was obtained.

Peer-Review: Externally peer-reviewed. 
Author Contributions: Conception/Design of Study- Y.K.D., S.Ö.; Data Acquisition- A.T., Ö.G.T.; Data Analysis/Interpretation- A.Ş.Y., Y.K.D.; Drafting Manuscript- Y.K.D., A.T., Ö.G.T.; Critical Revision of ManuscriptA.Ş.Y., S.Ö.; Final Approval and Accountability- Y.K.D., A.T., Ö.G.T., A.Ş.Y., S.Ö.

Conflict of Interest: Authors declared no conflict of interest.

Financial Disclosure: Authors declared no financial support

\section{REFERENCES}

1. Wetmore RF, Handler SD. Pediatric Tracheostomy Experience During the Past Decade. Ann Otol Rhinol Laryngol 1982;91(6 Pt 1):628-32.

2. Line WS, Hawkins DB, Kahlstrom EJ, MacLaughlin EF, Ensley JL. Tracheotomy in infants and young children: The changing perspective 1970-1985. Laryngoscope 1986;96(5):510-5.

3. Nassif C, Zielinski M, Francois M, Van Den Abbeele T. Tracheotomy in children: A series of 57 consecutive cases. Eur Ann Otorhinolaryngol Head Neck Dis 2015;132(6):321-5.

4. Can FK, Anıl AB, Anıl M, Gümüşsoy M, Çitlenbik H, Kandoğan T, et al. The outcomes of children with tracheostomy in a tertiary care pediatric intensive care unit in Turkey. Turk Pediatr Ars 2018;53(3):177-84.

5. Berry JG, Graham RJ, Roberson DW, Rhein L, Graham DA, Zhou J, et al. Patient characteristics associated with in-hospital mortality in children following tracheotomy. Arch Dis Child 2010;95(9):703-10.

6. Kremer B, Botos-Kremer Al, Eckel HE, Schlöndorff G. Indications, complications, and surgical techniques for pediatric tracheostomies - An update. J Pediatr Surg 2002;37(11):1556-62.

7. Gaudreau PA, Greenlick H, Dong T, Levy M, Hackett A, Preciado D, et al. Preventing complications of pediatric tracheostomy through standardized wound care and parent education. JAMA Otolaryngol Head Neck Surg 2016;142(10):966-71.

8. Ang AHC, Chua DYK, Pang KP, Tan HKK. Pediatric tracheotomies in an Asian population: The Singapore experience. Otolaryngol Head Neck Surg 2005;133(2):246-50.

9. De Trey L, Niedermann E, Ghelfi D, Gerber A, Gysin C. Pediatric tracheotomy: A 30-year experience. J Pediatr Surg 2013;48(7):1470-5.

10. Mahadevan M, Barber C, Salkeld L, Douglas G, Mills N. Pediatric tracheotomy: 17 year review. Int J Pediatr Otorhinolaryngol 2007;71(12):1829-35.

11. Hadfield PJ, Lloyd-Faulconbridge RV, Almeyda J, Albert DM, Martin Bailey $C$. The changing indications for paediatric tracheostomy. Int J Pediatr Otorhinolaryngol 2003;67(1):7-10.

12. Parrilla C, Scarano E, Guidi ML, Galli J, Paludetti G. Current trends in paediatric tracheostomies. Int J Pediatr Otorhinolaryngol 2007;71(10):1563-7.
13. Zenk J, Fyrmpas G, Zimmermann T, Koch M, Constantinidis J, Iro $\mathrm{H}$. Tracheostomy in young patients: Indications and long-term outcome. Eur Arch Oto-Rhino-Laryngology 2009;266(5):705-11.

14. Chan T, Devaiah AK. Tracheostomy in Palliative Care. Otolaryngol Clin North Am 2009;42(1):133-41.

15. Gergin O, Adil EA, Kawai K, Watters K, Moritz E, Rahbar R. Indications of pediatric tracheostomy over the last 30 years: Has anything changed? Int J Pediatr Otorhinolaryngol 2016;87:144-7.

16. Özmen S, Özmen ÖA, Ünal ÖF. Pediatric tracheotomies: A 37year experience in 282 children. Int J Pediatr Otorhinolaryngol 2009;73(7):959-61.

17. Walner DL, Loewen MS, Kimura RE. Neonatal subglottic stenosis Incidence and trends. Laryngoscope 2001;111(1):48-51.

18. Mirabile L, Serio PP, Baggi RR, Couloigner VV. Endoscopic anterior cricoid split and balloon dilation in pediatric subglottic stenosis. Int J Pediatr Otorhinolaryngol 2010;74(12):1409-14.

19. Blanchard M, Leboulanger N, Thierry B, Blancal JP, Glynn F, Denoyelle $F$, et al. Management specificities of congenital laryngeal stenosis: External and endoscopic approaches. Laryngoscope 2014;124(4):1013-8.

20. Léauté-Labrèze $C$, De La Roque ED, Hubiche T, Boralevi F, Thambo JB, Taïeb A. Propranolol for severe hemangiomas of infancy. N Engl J Med 2008;358(24):2649-51.

21. Fauroux B, Leboulanger N, Roger G, Denoyelle F, Picard A, Garabedian EN, et al. Noninvasive positive-pressure ventilation avoids recannulation and facilitates early weaning from tracheotomy in children. Pediatr Crit Care Med 2010;11(1):31-7.

22. Carr MM, Poje CP, Kingston L, Kielma D, Heard C. Complications in Pediatric Tracheostomies. Laryngoscope 2001;111(11):1925-8.

23. Atmaca S, Bayraktar C, Aşilioğlu N, Kalkan G, Özsoy Z. Pediatric tracheotomy: 3-year experience at a tertiary care center with 54 children. Turk J Pediatr 2011;53(5):537-40.

24. Colman KL, Mandell DL, Simons JP. Impact of stoma maturation on pediatric tracheostomy-related complications. Arch Otolaryngol Head Neck Surg 2010;136(5):471-4.

25. Carron JD, Derkay CS, Strope GL, Nosonchuk JE, Darrow DH. Pediatric Tracheotomies: Changing Indications and Outcomes. Laryngoscope 2000;110(7):1099-104.

26. Simma B, Spehler D, Burger R, Uehlinger J, Ghelfi D, Dangel P, et al. Tracheostomy in children. Eur J Pediatr 1994;153(4):291-6.

27. Dursun O, Ozel D. Early and long-term outcome after tracheostomy in children. Pediatr Int 2011;53(2):202-6.

28. Zia S, Arshad M, Nazir Z, Awan S. Pediatric tracheostomy: Complications and role of home care in a developing country. Pediatr Surg Int 2010;26(3):269-73.

29. Karapinar B, Arslan MT, Ozcan C. Pediatric bedside tracheostomy in the pediatric intensive care unit: six-year experience. Turk J Pediatr 2008;50(4):366-72. 